\title{
Factorial Design for Evaluation of Reagent Concentrations on Silver Nanoparticles Stability
}

\author{
Monise Cristina Ribeiro Casanova*, Gabriella Silva Ferreira, Amanda Novais de Abreu, \\ Deangelis Damasceno
}

Instituto Federal de Educação, Ciência e Tecnologia de Goiás - Senador Canedo, Senador Canedo, 75261-331,

Goiás, Brazil. *monise.coltro@ifg.edu.br

Nanomaterials, especially silver nanoparticles (AgNps) offer unique optical, chemical and physical properties when compared to properties of bulk materials due to their plasmonic ressonance band. Despite AgNps synthesis by chemical reduction is not new, their stability is a crucial factor for a good applicability. AgNps were characterized by UV-vis spectroscopy. Different reports found in literature related to concentrations of used reagents in nanoparticles synthesis are scares when one take into account the high control that is required to avoid nanoparticles aggregation. This study aims to evaluate the concentrations of the reducing agent $-\mathrm{NaBH}_{4}$ (factor a), stabilizing agent - PVA (factor b) and $\mathrm{AgNO}_{3}$ (factor $\mathrm{c}$ ) through a factorial design $2^{3}$ with three center points of face centered to evaluate the influence of reagents and their concentrations on AgNps stability. The interaction between factors "a" and "c" showed a positive significant value when concentrations are modified from level (-) to level (+) of these two variables. It can be observed an increase of plasmonic band absorption peaks of $18.4 \%$ indicating synergism between variables a and c. However, one can notice a decrease of 3.91\% of peak's incidence when factor "b" concentrations are increased. It can be inferred that low PVA concentrations $(\leq 0.5 \%)$ assist the AgNps stability and above this value PVA acts as a chemical inhibitor. Analysis of variance indicated a coded quadratic model of second order. Plots of response surface showed that the ideal synthesis of $\mathrm{AgNps}$ happens on the ratio $\mathrm{NaBH}_{4}(\mathrm{mmol})$ : $\mathrm{PVA}(\%)$ : $\mathrm{AgNO}_{3}(\mathrm{mmol})$ of 4:1:2.

Keywords: Chemometrics, Nanotechnology, Nanoscale, Spectroscopy.

\section{INTRODUCTION}

Nanotechnology is a rapidly expanding field, focused on the creation of functional materials, devices, and systems through the control of matter on the nanometer scale, and the exploitation of novel phenomena and properties at that length scale [1]. It is a target of interest of the scientific community in the last decade. The term is defined as the control of matter in the atomic or molecular level in the size range where at least one of the nanomaterials dimensions is between 1 and 100 nanometers [1]. When dimensions of a material decrease to a smaller size, its properties remain the same at first but have small changes. But then, decreasing size to less than $100 \mathrm{~nm}$, properties of the materials change drastically.

Nanomaterials have an outstanding behavior for having a broad range of applications in areas like medicine, agriculture, pharmacy and cosmetics [2] among others. In food industry, e.g. it helps to keep food in ideal conservatory conditions $[3,4]$ or flexibility properties improvement for food packaging, in pharmaceutical area it can be used as vectorization of anticancer drugs and antibiotics [5,6] for example, and in medical field being used for the treatment of cavities interrupting the process of inflammation either preventing cavities or detecting them in early stages $[7,8]$.

Among metallic nanoparticles, silver nanoparticles stand out once in nanometric scale they have a variety of applications in sensors, electronic chips among others. Besides, in the medical field, they have bactericidal [9] and fungicide properties. Nowadays, AgNps are used in the treatment of mycoses and cavities.

Since antiquity, silver properties were already known by Greeks and Romans who used it as antibiotics. 
Its great advantage lies in the fact that individuals throughout life need long term use of antibiotics which brings the emergence of resistant super bacteria to antibiotics [10], then the use of nanoparticles is a very promising alternative. Silver nanoparticles are being used in numerous technologies and incorporated into a wide array of consumer products that take advantage of their desirable optical, conductive, and antibacterial properties. For diagnostic applications, silver nanoparticles are used in biosensors where they can be used as biological tags for quantitative detection. For antibacterial applications, silver nanoparticles are incorporated in apparel, footwear, paints, wound dressings, appliances, cosmetics, and plastics for their antibacterial properties [10]. AgNps can also be used in conductive inks and integrated into composites to enhance thermal and electrical conductivity.

Silver nanoparticles can be prepared by chemical and physical methods. Among chemical methods, electrochemical and photochemical methods stand out. Studies show that experimental conditions, interaction kinetics of metallic ions with reducing agents, and adsorption processes of the stabilizing agents with nanoparticles influence size, stability, and properties of metallic nanoparticles [11]. Therefore, choosing the preparing method of nanoparticles as well as reducing agent and the stabilizing agent is essential for a successful synthesis.

The chemical reduction method is the most used one to prepare silver nanoparticles as colloidal dispersions in water or organic solvents. This method outstands itself among others once it is fast, cheap and does not require organic solvents, becoming a method less harmful for the environment. It consists of chemical reduction of silver ions - which comes from the used silver salt - to silver atoms followed by agglomeration in "clusters" [12]. As the synthesis of silver nanoparticles is a redox reaction, it is crucial to choose the most appropriate reducing agent. Reducing agents that are commonly used are sodium borohydride, sodium citrate, ascorbic acid, and hydrogen. Previous studies show that the use of strong reducing agents besides increasing the redox reaction velocity, as sodium borohydride, form monodisperse smaller particles, but larger nanoparticles are more difficult to control $[11,13]$. On the other hand, the use of weaker reducing agents leads to larger nanoparticles with wider size distribution [14].

To synthesize silver nanoparticles through chemical reduction method it is extremely important to apply a stabilizing agent capable of restraining nanoparticles aggregation/agglomeration of colloids. The chosen stabilizing agent was polyvinyl alcohol (PVA). According to Sharma and coworkers [15], PVA is an environment friendly polymer once it is water soluble and it has extremely low toxicity. It is often used as a stabilizer due to its optical clarity [16], which allows investigation of nanoparticles formation.

Despite silver nanoparticles synthesis is not new, their stability is a crucial factor for their good applicability. Factors such as reagents concentration is one of them. The synthesis of AgNps is related to obtaining of AgNps with uniform distribution and high stability due to their tendency of agglomeration in aqueous solutions. In this matter, AgNps were prepared and characterized by UV-vis spectroscopy an indicative of chemical stability of AgNps are narrow peaks with high absorbance values.

Studies in literature make use of reagents concentrations for AgNps synthesis following protocols previously established based on empiric nanoparticles size and format results or scarse reports in synthesis procedures details or either the choice of reagents concentrations seems mechanic or random if one takes into account the required high control level to avoid particles aggregation. Optimization of synthesis parameters such as reagents concentrations allows the obtaining of silver nanoparticles with high stability which is very important to several silver nanoparticles applications. As nature and concentration of reducing and stabilizing agents greatly influence the functional properties of silver nanoparticles and as we deal with different parameters to synthesize stable nanoparticles, a factorial design seems proper to give us the optimum ratio between reagents concentrations. For that matter, factorial design was shown to be an important tool to increase the sensitivity of an analytical method, enabling optimization of the concentrations of reagents used to obtain silver nanoparticles or either optimize production levels of stabilizers for silver nanoparticles synthesis. 
As an example, Bittar and coworkers [17] were successful on the determination of the optimized experimental conditions for the development of a simple and low-cost process for the production of stable silver nanoparticles using factorial design (central composite design with five levels with four central points) for the determination of melamine in milk products at concentrations that may be harmful to human health. They found the best reagents concentrations for $\mathrm{AgNps}$ synthesis were $\mathrm{AgNO}_{3}$ and $\mathrm{NaBH}_{4}$ were $3.00 \times 10^{-3} \mathrm{~mol} \mathrm{~L}^{-1}$ and $1.25 \times 10^{-3} \mathrm{~mol} \mathrm{~L}^{-1}$, respectively.

El-Naggar et al. [18] have chosen factorial design to determine the combined effects of four process variables $\left(\mathrm{AgNO}_{3}\right.$ concentration, incubation period, $\mathrm{pH}$ level and inoculum size) on the extra-cellular biosynthesis of silver nanoparticles by Streptomyces viridochromogenes. Results showed that the maximum biosynthesis of silver nanoparticles was achieved at a concentration of $0.5 \%(\mathrm{v} / \mathrm{v})$ of $1 \mathrm{mM}$ $\mathrm{AgNO}_{3}$, an incubation period of $96 \mathrm{~h}$, an initial $\mathrm{pH}$ of 9 and inoculum size of $2 \%(\mathrm{v} / \mathrm{v})$. After optimization, the biosynthesis of silver nanoparticles was improved by approximately 5-fold as compared to that of the unoptimized conditions.

Sathiyanarayanan and coworkers [19] used a central composite design (CCD) of 32 experiments (5-level-4-factorial) with six central points to statistically optimize the production of a bioflocculant from marine sponges - used as a stabilizer - with most significant factors such as palm jaggery, $\mathrm{NH}_{4} \mathrm{NO}_{2}$, $\mathrm{K}_{2} \mathrm{HPO}_{4}$ and $\mathrm{NaCl}$ for the synthesis of silver nanoparticles. The maximum bioflocculant production obtained with statistically optimized medium was $13.42 \mathrm{~g} \mathrm{~L}^{-1}$.

Therefore, this study aims to evaluate silver nitrate $\left(\mathrm{AgNO}_{3}\right)$, reducing agent $\left(\mathrm{NaBH}_{4}\right)$ and stabilizing agent (PVA) through a factorial design $2^{3}$ with three central points face centered to evaluate the influence of reagents and their respective concentrations on AgNps stability.

\section{MATERIALS AND METHODS \\ Chemicals}

PVA (MW 61,000) and sodium borohydride granulate (10-40 mesh, 98\%) were purchased from Sigma-Aldrich (St. Louis, MO, USA). Silver nitrate was purchased from Vetec (Duque de Caxias, RJ, Brazil). All chemicals were used as received, without further purification.

\section{Methods}

\section{Characterization}

For characterization of AgNps, UV-vis spectroscopy was used to evaluate Nps optical characteristics as well as size. Transmission Electron Microscopy (TEM) was used to evaluate the size and shape of synthesized silver nanoparticles.

\section{Silver nanoparticles synthesis}

To synthesize silver nanoparticles, $10 \mathrm{~mL}$ of silver nitrate solution (solution a) were added to an Erlenmeyer. Then, $2 \mathrm{~mL}$ of polyvinyl alcohol solution (solution b) was added to solution a. And finally, a sodium borohydride solution was added slowly (drop wise) to the mixture (solution a and solution b) until a light-yellow color could be observed indicating the formation of silver nanoparticles. These reagents concentrations (solution $a, b$ and $c$ ) were varied.

\section{UV-vis spectroscopy}

Silver nanoparticles solutions were diluted in deionized water $(1: 10 \mathrm{v} / \mathrm{v})$ to obtain UV-vis spectra. Readings were performed in quartz bucket on UV-vis Hitachi spectrophotometer.

\section{Transmission Electron Microscopy}

Transmission electron microscopy (TEM) study for the characterization of particles were carried out by placing a drop of silver solution onto a carbon film supported on a copper grid followed by solvent evaporation under vacuum. Samples were studied using Jeol, JEM-2100 TEM, equipped with EDS, Thermo Scientific. 


\section{Design Factor}

For statistical analysis MATLAB ${ }^{\circledR}$ - based program was used to study the effects of the reagent concentrations on the formation of the Ag nanoparticles. A complete factorial design $2^{3}$ was prepared, with three centric face centered.

The use of a complete factorial design provides an extended study of the influence of each variable, providing a mathematical model and a response surface that allows to establish greater control of the working conditions.

Table I shows the studied factors and their respective levels. Experiments were performed randomly to avoid systematic errors. The measured responses were the absorbance peaks with wavelengths between 300 and $500 \mathrm{~nm}$, corresponding to the maximum absorption of the synthesized silver nanoparticles

Table I. Real and encoded levels for factorial design $2^{3}$

\begin{tabular}{ccccc}
\hline Factor & Variable & Level (-) & Level (0) & Level (+) \\
\hline $\mathrm{A}$ & $\mathrm{NaBH}_{4}(\mathrm{mmol})$ & 2.0 & 3.0 & 4.0 \\
$\mathrm{~B}$ & $\mathrm{PVA}(\% \mathrm{~m} / \mathrm{v})_{\mathrm{C}}$ & 0.5 & 1.0 & 1.5 \\
$\mathrm{C}$ & $\mathrm{AgNO}_{3}(\mathrm{mmol})$ & 1.0 & 1.5 & 2.0 \\
\hline
\end{tabular}

Data in factorial design were statistically evaluated through analysis of variance (ANOVA) and used for the construction of response surface plots.

\section{RESULTS AND DISCUSSION \\ Silver nanoparticles synthesis}

Silver nanoparticles were obtained through oxidation reduction reaction between silver nitrate (oxidant agent) and sodium borohydride (reducing agent) according to the chemical reaction in Equation 1.

$$
\mathrm{AgNO}_{3}(\mathrm{aq})+\mathrm{NaBH}_{4}(\mathrm{aq}) \rightarrow \mathrm{Ag}+1 / 2 \mathrm{H}_{2}(\mathrm{~g})+1 / 2 \mathrm{~B}_{2} \mathrm{H}_{6}(\mathrm{~g})+\mathrm{NaNO}_{3}(\mathrm{aq})
$$

After the synthesis of silver nanoparticles, a yellow color was observed indicating their formation. When colloidal particles are much smaller than visible light wavelength, solutions present a yellow color with an intense plasmonic band in the range from 380 to $400 \mathrm{~nm}$ and others less intense bands in the absorption spectra [15]. As the chemical reaction for synthesis of silver nanoparticles is an oxidation reduction reaction, the reagents silver nitrate (oxidizing agent), sodium borohydride (reducing agent) are essential for the formation of silver nanoparticles. However, one can notice a low stability, which means their nanoparticles aggregate easily. The latter can be observed for silver nanoparticles that make use of only silver nitrate and sodium borohydride, where the solution shows a grey color, indicating aggregation and coalescence of nanoparticles. Due to the later, the use of a stabilizing agent was chosen, capable of containing nanoparticles aggregation. The chosen stabilizing agent was PVA. According to Sharma and coworkers [15], PVA is a very interesting polymer to be used once it is water soluble and has extremely low toxicity. It is frequently used as a stabilizer due to its optical clarity, which allows investigation of nanoparticle formation. Solutions prepared with PVA showed a dark yellow color.

Despite silver nanoparticles synthesis via chemical reduction is not new, stability is a crucial factor for their good applicability. On this purpose, a great variety of variables can influence silver nanoparticles stability such as reagents concentration, temperature, stocking conditions.

A successful synthesis of AgNps is attached to obtaining AgNps with uniform distribution and high 
stability due to its tendency of agglomerate in aqueous solutions. In this study, concentration of silver nitrate, sodium borohydride and PVA varied during synthesis in order to understand the influence of their concentrations on AgNps stability and to find the great ratio between reagents concentrations that synthesize the smaller and most stable AgNps.

\section{Silver nanoparticles characterization}

Synthesized AgNps were characterized through transmission electron microscopy (TEM) and UVvis spectroscopy. Through UV-vis analysis, spectra showed surface plasmonic bands characteristics of silver nanoparticles. Figure 1 shows spectra in the UV-vis region of synthesized AgNps. AgNps solutions that contain PVA in their composition showed a narrower surface plasmonic band when compared to the AgNps solution without PVA, indicating the formation of smaller AgNps thus more stable due to the presence of PVA. Besides, in the solutions where concentrations of $\mathrm{AgNO}_{3}$ was $2 \mathrm{mM}$ and $\mathrm{NaBH}_{4}$ was $4 \mathrm{mM}$ it was noticed a bigger influence of PVA on AgNPs stability.

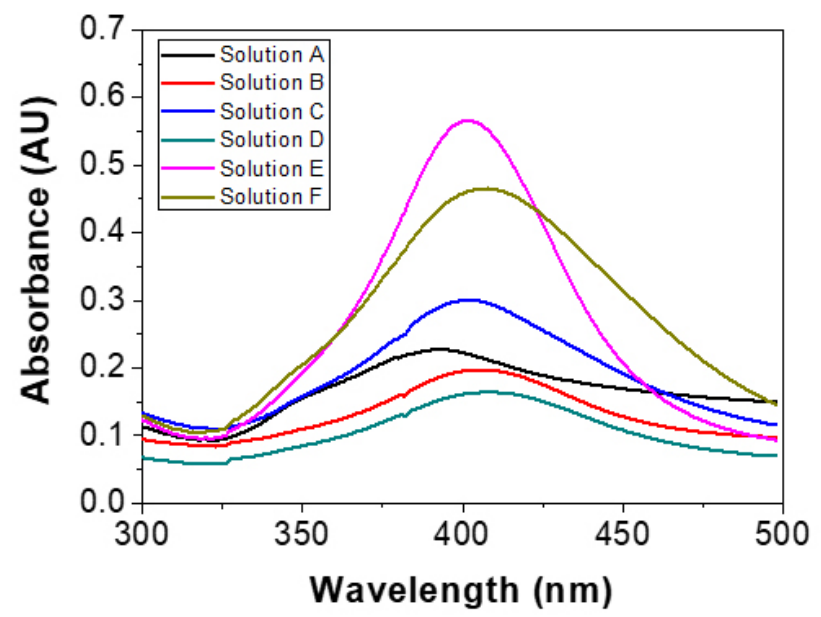

Figure 1. UV/Vis spectra recorded for solutions $\mathrm{A}\left(2 \mathrm{mM} \mathrm{AgNO}_{3}, 4 \mathrm{mM} \mathrm{NaBH}\right)$, $\mathrm{B}\left(1 \mathrm{mM} \mathrm{AgNO}{ }_{3}, 2 \mathrm{mM}\right.$ $\mathrm{NaBH}_{4}, 0.5 \% \mathrm{~m} / \mathrm{v} \mathrm{PVA}$ ), C ( $\left.1 \mathrm{mM} \mathrm{AgNO}_{3}, 4 \mathrm{mM} \mathrm{NaBH}_{4}, 0.5 \% \mathrm{~m} / \mathrm{v} \mathrm{PVA}\right), \mathrm{D}\left(1 \mathrm{mM} \mathrm{AgNO}_{3}, 2 \mathrm{mM} \mathrm{NaBH}_{4}, 1.5 \%\right.$ $\mathrm{m} / \mathrm{v}$ PVA), E (2 $\left.\mathrm{mM} \mathrm{AgNO}_{3}, 4 \mathrm{mM} \mathrm{NaBH}{ }_{4}, 0.5 \% \mathrm{~m} / \mathrm{v} \mathrm{PVA}\right)$ and F (2 $\left.\mathrm{mM} \mathrm{AgNO}_{3}, 4 \mathrm{mM} \mathrm{NaBH}_{4}, 1.5 \% \mathrm{~m} / \mathrm{v} \mathrm{PVA}\right)$.

Transmission electron microscopy (TEM) images of AgNps solutions were obtained as shown in Figure 2. AgNps without PVA agglomerate more when compared to others with PVA and AgNps with PVA concentration $1.5 \%$ are more disperse than the ones with PVA concentration $0.5 \%$.

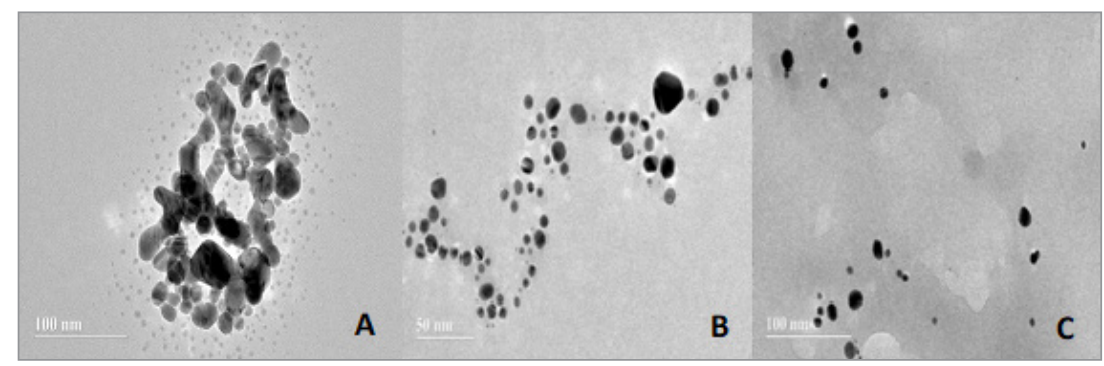

Figure 2. Transmission electron microscopy of AgNps solutions $\mathrm{A}$ ( $2 \mathrm{mM} \mathrm{AgNO}_{3}, 4 \mathrm{mM} \mathrm{NaBH}$ ), B (2 $\left.\mathrm{mM} \mathrm{AgNO}_{3}, 4 \mathrm{mM} \mathrm{NaBH}{ }_{4}, 0,5 \% \mathrm{~m} / \mathrm{v} \mathrm{PVA}\right)$ and C (2 $\left.\mathrm{mM} \mathrm{AgNO}_{3}, 4 \mathrm{mM} \mathrm{NaBH}_{4}, 1,5 \% \mathrm{~m} / \mathrm{v} \mathrm{PVA}\right)$.

Although concentrations of silver nitrate, sodium borohydride and PVA varied for silver nanoparticles synthesis, UV-vis spectra and transmission electron microscopy images were not enough to provide a detailed picture of the influence of these reagent concentrations on the stability of silver nanoparticles. 


\section{Factorial design}

Therefore, in this study a factorial design $2^{3}$ with 03 centric face centered was performed to evaluate the influence of reagents and their respective concentrations on AgNps stability [20]. The studied variables and their respective levels are presented in Table II, besides absorbance results.

With factorial design it was verified that absorbance values increased with the increase of concentrations of factor $a$ and $c$, besides the interaction of these independent variables. This can be better noticed in Figure 3, where variables effect and their interactions is presented showing the standardized values (absolute values) obtained in factorial design of each parameter. The size of the bars shows the impact of the parameters in the process. These three parameters exceed the t-value limit [21] and have significant positive values which indicates increase of AgNps stability. It is remarkable that the interaction between factors a and c present a significant and positive value when concentrations modify from level (-) to level (+) of these two variables.

Table II: Real and coded values for factorial design $2^{3}$ with 03 centric face centered for AgNps synthesis and absorbance results

\begin{tabular}{ccccc}
\hline \multirow{3}{*}{ Experiments } & \multicolumn{3}{c}{ Factors } & $\begin{array}{c}\text { Absorbance } \\
\text { responses (a.u.) }\end{array}$ \\
\cline { 2 - 4 } & $\mathbf{X}_{\mathbf{a}}$ & $\mathbf{X}_{\mathbf{b}}$ & $\mathbf{X}_{\mathbf{c}}$ & 0.650 \\
2 & -1 & -1 & -1 & 0.435 \\
3 & 1 & -1 & -1 & 0.452 \\
4 & -1 & 1 & -1 & 0.396 \\
5 & -1 & -1 & 1 & 0.440 \\
6 & 1 & 1 & -1 & 0.804 \\
7 & 1 & -1 & 1 & 0.457 \\
8 & -1 & 1 & 1 & 0.751 \\
9 & 1 & 1 & 1 & 0.881 \\
10 & 0 & 0 & 0 & 0.872 \\
11 & 0 & 0 & 0 & 0.813 \\
12 & 0 & 0 & 0 & 0.770 \\
13 & -1 & 0 & 0 & 0.660 \\
14 & 1 & 0 & 0 & 0.712 \\
15 & 0 & -1 & 0 & 0.603 \\
16 & 0 & 1 & 0 & 0.732 \\
17 & 0 & 0 & -1 & 0.773 \\
\hline
\end{tabular}




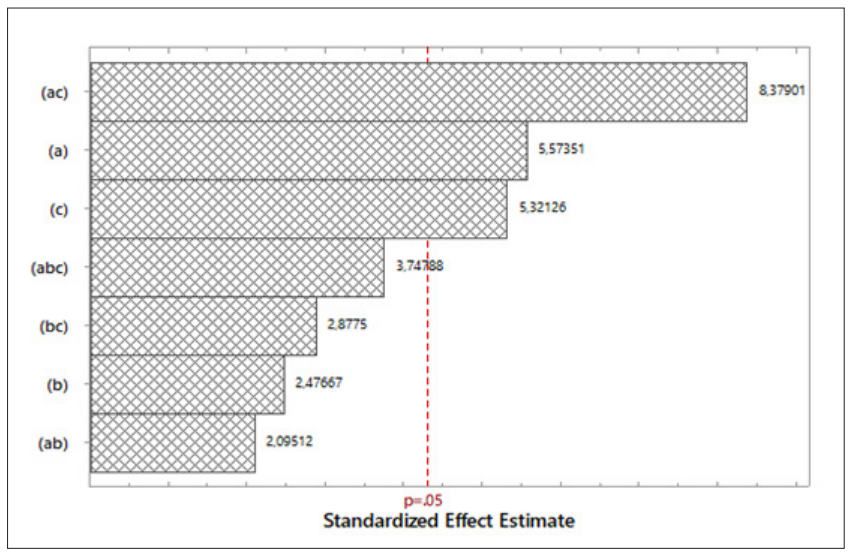

Figure 3. Pareto chart with standardized effects for factorial design performed for silver nanoparticle synthesis.

It was observed an increase of absorbance peaks of plasmonic resonance bands of $18.4 \%$ indicating synergism between these two variables. However, there was a decrease of $3.91 \%$ on peaks incidence when there is an increase on factor $b$ concentrations. It can be inferred that low concentrations of PVA $(\leq 0.5 \%)$ support AgNps stability and above this value, PVA acts as an inhibitor in the formation of AgNPs. Model was validated through analysis of variance (ANOVA), in Table III.

Table III. ANOVA results for second-order non-linear model

\begin{tabular}{lccccc}
\hline & DF & Adj. SS & Adj. MS & $F$-value & $P$-value \\
\hline Model & 10 & 0,402517 & 0,040252 & 7,32 & 0,012 \\
(a) & 1 & 0,013309 & 0,013309 & 2,42 & 0,171 \\
(b) & 1 & 0,00867 & 0,00867 & 1,58 & 0,256 \\
$(\mathrm{c})$ & 1 & 0,022178 & 0,022178 & 4,03 & 0,091 \\
$(\mathrm{ab})$ & 1 & 0,00098 & 0,00098 & 0,18 & 0,688 \\
$(\mathrm{ac})$ & 1 & 0,107882 & 0,107882 & 19,61 & 0,004 \\
(bc) & 1 & 0,005043 & 0,005043 & 0,92 & 0,375 \\
(abc) & 1 & 0,012442 & 0,012442 & 2,26 & 0,183 \\
(aa) & 1 & 0,020704 & 0,020704 & 3,76 & 0,1 \\
(bb) & 1 & 0,056289 & 0,056289 & 10,23 & 0,019 \\
(cc) & 1 & 0,006721 & 0,006721 & 1,22 & 0,311 \\
Error & 6 & 0,033012 & 0,005502 & & \\
Lack of fit & 4 & 0,0303 & 0,007575 & 5,59 & 0,158 \\
Pure Error & 2 & 0,002712 & 0,001356 & & \\
Total & 16 & 0,43553 & & & \\
\hline
\end{tabular}

According to Table III, ANOVA interpretation indicates that the model is well adjusted ( $p$ value $<0.05$ ). The curvature on the response surface was statistically significant ( $p$ value $>0.05$ ), indicating that the model did not show a lack of fit. Figure 4 shows random behavior of the residues along the absorbance values predicted by the model. 


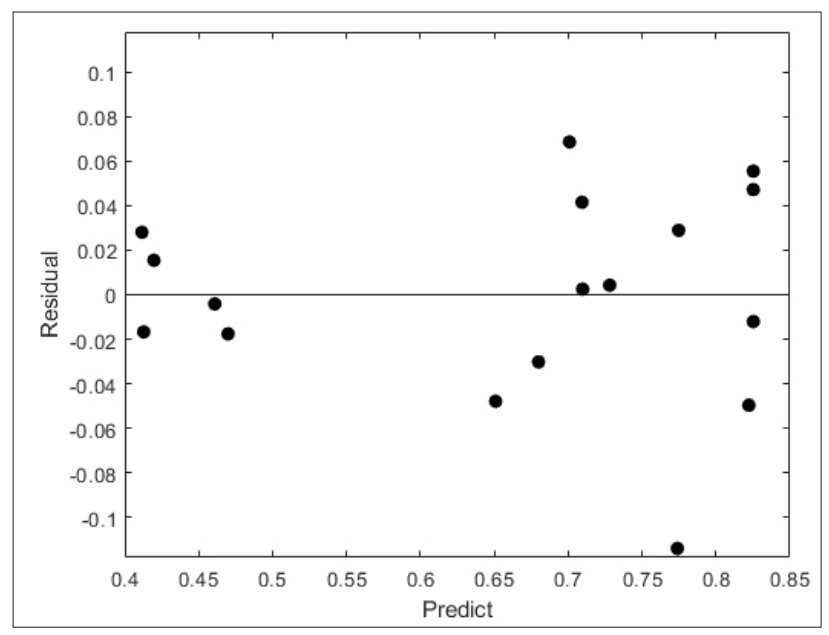

Figure 4. Residues chart according to the absorbance values predicted by the model.

Considering the statistical relevance between the factors and their interactions described in Table III, Equation 2 represents the second-order non-linear coded model which describes the absorbance response due to the interaction of concentrations of $\mathrm{NaBH}_{4}$ and $\mathrm{AgNO}_{3}$, with values of $\mathrm{R}^{2}$ and adjusted $R^{2}$ respectively.

$$
A b=0.825( \pm 0.077)+0.1161( \pm 0.063) a c-0.1449( \pm 0.1101) b^{2}
$$

where $\mathrm{Ab}$ is absorbance (a.u.), a represents $\mathrm{NaBH}_{4}$ concentration, $\mathrm{c}$ is $\mathrm{AgNO}_{3}$ concentration, and b is PVA concentration, $\mathrm{R}^{2}$ is $92,42 \%$ and adjusted $\mathrm{R}^{2}$ is $79,79 \%$. Equation 2 shows the strong influence of the increase of concentration of these two factors and also that silver nanoparticles stability was significantly influenced by decrease of PVA concentration.

Response surface plots [22-24] using quadratic models were proposed to describe the behavior of silver nonoparticulate synthesis where two variables fluctuate along the experimental levels. Figure 5 shows absorbance variation when $\mathrm{AgNO}_{3}$ concentration is fixed on (-) Figure $5 \mathrm{a},(0)$ Figure $5 \mathrm{~b}$ and $(+)$ Figure 5c. The vertex corresponding to level $(+1)$ of the factor increases with increase of factor c. Throughout the experiment, this difference increases, corroborating to the synergism between factors $a$ and $\mathrm{c}$. When analyzing Figure $5 \mathrm{a}$ and setting $\mathrm{AgNO}_{3}$ concentration to its lowest value, the stability of AgNps are favored in lower concentrations of $\mathrm{NaBH}_{4}$ and PVA. It is inferred that PVA at lower concentrations functions as a surfactant aiding the stability of AgNps. In Figures $5 b$ and $5 c$ one can notice that PVA still favors the obtaining of stable AgNps until its concentration reaches the center point and above that point the AgNps aggregate. It could be noticed that PVA concentration (factor $b$ ) contributed to the AgNps stabilization until level (0). Above this level, one can infer high concentration of PVA polymer inhibits AgNps synthesis. 
(A)

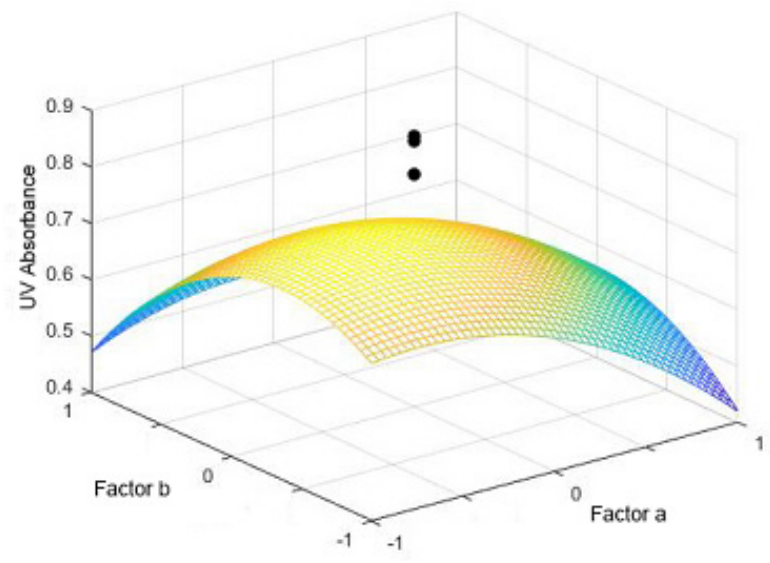

(B)

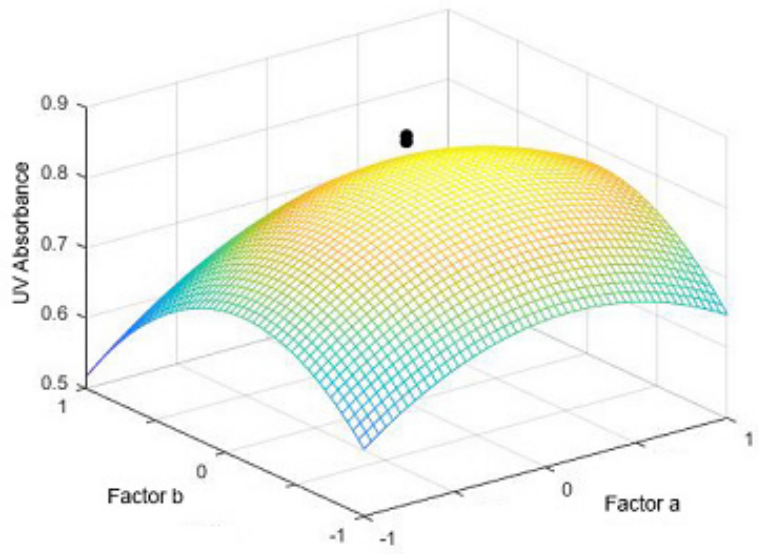

(C)

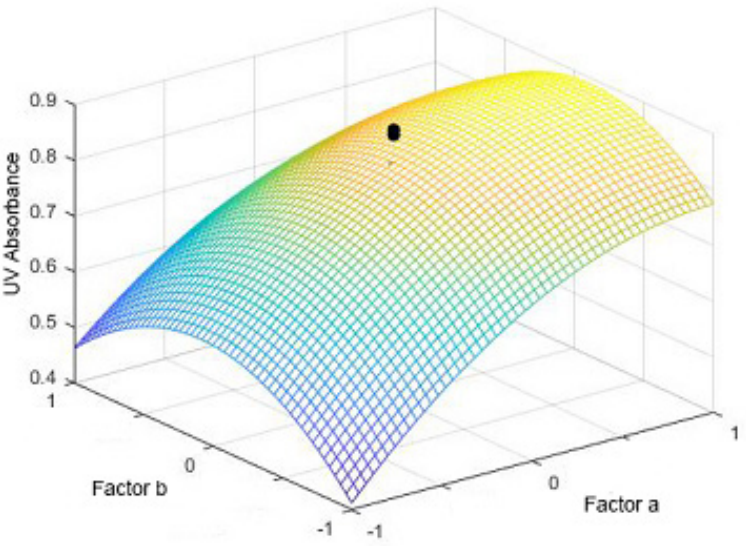

Figure 5. Response surface plots to the quadratic model as a function of factors "a" and "b" and factor "c" fixed on (A) level (-), (B) level (0) and (C) level (+).

According to this study, it can be noticed that synthesis of AgNps happens on the ratio $\mathrm{NaBH}_{4}(\mathrm{mmol})$ : PVA (\%): $\mathrm{AgNO}_{3}(\mathrm{mmol})$ of 4:1:2, which will generate smaller and more stable AgNps.

\section{CONCLUSIONS}

We have successfully reported herein the use of complete factorial design $2^{3}$ with three centric face centered for evaluation of the influence of the reducing agent $-\mathrm{NaBH}_{4}$ (factor a), stabilizing agent - PVA (factor b) and $\mathrm{AgNO}_{3}$ (factor c) concentrations on silver nanoparticles stability. UV-vis spectra showed 
characteristic surface plasmonic bands of AgNps, indicating successful nanoparticles synthesis. The presence of PVA in composition lead to smaller and more stable nanoparticles. Factorial design results showed that the interaction between factors a and $c$ present a significant and positive value when concentrations modify from level (-) to level $(+)$ of these two variables. Besides, absorbance peaks of plasmonic resonance bands analysis infers that low concentrations of PVA $(\leq 0.5 \%)$ support AgNps stability and above this value, PVA acts as an inhibitor in the formation of AgNPs.

Response surface plots using quadratic models described that PVA concentration (factor b) contributed to the AgNps stabilization until level (0). Above this level, one can infer high concentration of PVA polymer inhibits AgNps synthesis. Therefore, it can be suggested that synthesis of AgNps happens on the ratio $\mathrm{NaBH}_{4}(\mathrm{mmol})$ : $\mathrm{PVA}(\%): \mathrm{AgNO}_{3}(\mathrm{mmol})$ of $4: 1: 2$, which will generate smaller and more stable AgNps.

Manuscript submitted: Dec. 2, 2018; revised manuscript submitted: Feb. 12, 2019; manuscript accepted: March 11, 2019; published online: June 21, 2019.

\section{REFERENCES}

1. Bhushan, B. Introduction to Nanotechnology. In: Handbook of nanotechnology. $4^{\text {th }}$ Edition. Springer, 2017.

2. Sharma, G.; Kumar, A.; Sharma, S.; Naushad, M.; Dwivedi, R. P.; Alothman, Z. A.; Mola, G. T. J. King Saud Univ., Sci. In Press, 2017 (DOI: https://doi.org/10.1016/j.jksus.2017.06.012).

3. Souza, V. G. L.; Fernando, A. L. Food Packaging and Shelf Life, 2016, 8, pp. 63-70 (DOI: https://doi.org/10.1016/j.fpsl.2016.04.001).

4. Moura, M. R.; Mattoso, L. H. C.; Zucolotto, V. J. Food Eng., 2012,109 (3), pp. 520-524 (DOI: https://doi.org/10.1016/j.jfoodeng.2011.10.030).

5. Kim, T.; Braun, G. B.; She, Z.; Hussain, S.; Ruoslahti, E.; Sailor, M. J. ACS Appl. Mater. Interfaces, 2016, 8 (44), pp 30449-30457 (DOI: https://doi.org/10.1021/acsami.6b09518).

6. Hussain, S.; Joo, J.; Kang, J.; Kim, B.; Braun, G. B.; She, Z.; Kim, D.; Mann, A. M.; Mölder, T.; Teesalu, T.; Carnazza, S.; Guglielmino, S.; Sailor, M. J.; Ruoslaht, E. Nature Biom. Eng., 2018, 2, pp 95-103 (DOI: https://doi.org/10.1038/s41551-017-0187-5).

7. Noronha, V. T.; Paula, A. J.; Durán, G.; Galembeck, A.; Cogo-Muller, K.; Franz-Montan, M.; Durán, N. Dent. Mater., 2017, 33 (10), pp 1110-1126 (DOI: https://doi.org/10.1016/j.dental.2017.07.002).

8. Freire, P. L. L.; Stamford, T. C. M.; Albuquerque, A. J. R.; Sampaio, F. C.; Cavalcante, H. M. M.; Macedo, R. O.; Galembeck, A.; Flores, M. A. P.; Rosenblatt, A. Int. J. Antimicrob. Agents., 2015, 45 (2) pp 183-187 (DOI: https://doi.org/10.1016/j.ijantimicag.2014.09.007).

9. Prabhu, S.; Poulose, E. Int Nano Lett, 2012, 2:32, pp 1-10. (DOI:https://doi.org/10.1186/22285326-2-32)

10. Abou El-Nour, K. M. M.; Eftaiha, A.; Al-Warthan, A.; Ammar, R. A. A. Arabian J. Chem., 2010, 3 (3), pp 135-140 (DOI: https://doi.org/10.1016/j.arabjc.2010.04.008).

11. Rafique, M.; Sadaf, I.; Rafique, M. S.; Tahir, M. B. Artif. Cells, Nanomed., Biotechnol., 2017, 45 (7), pp. 1272-1291 (DOI: https://doi.org/10.1080/21691401.2016.1241792).

12. Ozyurek, M.; Gungor, N.; Baki, S.; Guçlu, K.; Apak, R. Anal. Chem., 2012, 84 (18), $8052-8059$ (DOI: https://doi.org/10.1021/ac301925b).

13. Kakkar, R.; Sherly, E. D.; Madgula, K.; Devi, D. K.; Sreedhar, B. J. Appl. Polym. Sci., 2012, 126, pp 154-161 (DOI: https://doi.org/10.1002/app.36727).

14. Lee, P. C.; Meisel, D. J. Phys. Chem., 1982, 86 (17), pp 3391-3395

(DOI: https://doi.org/10.1021/j100214a025).

15. Sharma, V., Yngard, R., Lin, Y. Adv. Colloid Interface Sci., 2009,145, pp 83-96 (DOI: https://doi.org/10.1016/j.cis.2008.09.002). 
16. Hallensleben, M.; Fuss, R.; Mummy, F. Polyvinyl Compounds, Others. Ullman's Encyclopedia of Industrial Chemistry. Wiley Library, UK, 2015, pp 1-23.

17. Bittar, D. B.; Catelani, T. A.; Nigoghossian, K.; Barud, H. S.; Ribeiro, S. J. L.; Pezza, L.; Pezza, H. R. Anal. Lett., 2017, 50 (5), pp 829-841. (DOI: https://doi.org/10.1080/00032719.2016.1196213)

18. El-Naggar, N. E.; Abdelwahed, N. A. M. J. Microbiol., 2014, 52 (1), pp. 53-63 (DOI: https://doi.org/10.1007/s12275-014-3410-z).

19. Sathiyanarayanan, G.; Kiran, G. S.; Selvin, J. Colloids Surf. B., 2013, 102 (1), pp 13-20 (DOI: https://doi.org/10.1016/j.colsurfb.2012.07.032).

20. Breitkreitz, M., Souza, A., Poppi, R. Quim. Nova. 2014, 37 (3), pp 564-573 (DOI: https://doi.org/10.5935/0100-4042.20140071).

21. Rigon, R. B.; Gonçales, M. L.; Severino, P.; Alves, D. A.; Santana, M. H. A.; Souto, E. B.; Chorilli, M. Colloids Surf., B., 2018,171, pp 501-505 (DOI: https://doi.org/10.1016/j.colsurfb.2018.07.065).

22. Wang, C.; Wang, H.; Zhao, D.; Wei, X.; Li, X.; Liu, W.; Liu, H. Sensors, 2019, 19 (3), 615 (DOI: https://doi.org/10.3390/s19030615).

23. Aly-Eldeen, M. A.; El-Sayed, A. A. M.; Salem, D. M. S. A.; Zokm, G. M. Egypt. J. Aquat. Res., 2018, 44, pp 179-186 (DOI: https://doi.org/10.1016/j.ejar.2018.09.001).

24. Vicentini, F. C.; Figueiredo-Filho, L. C. S.; Janegitz, B. C.; Santiago, A., Pereira-Filho, E. R.; Fatibello-Filho, O. Quim. Nova. 2011, 5, pp 825-830 (DOI: https://doi.org/10.1590/S010040422011000500018). 